J Pediatr. 2016 April ; 171: 196-201.e1. doi:10.1016/j.jpeds.2015.12.079.

\title{
Kidney Disease Progression in Autosomal Recessive Polycystic Kidney Disease
}

\author{
Katherine M Dell, M.D. ${ }^{1}$, Matthew Matheson, M.S. ${ }^{2}$, Erum A. Hartung, M.D. ${ }^{3}$, Bradley A. \\ Warady, M.D. ${ }^{4}$, Susan L. Furth, M.D., Ph.D. ${ }^{3}$, and on behalf of the Chronic Kidney Disease in \\ Children (CKiD) Study ${ }^{*}$ \\ ${ }^{1}$ Center for Pediatric Nephrology, Cleveland Clinic Children's, Department of Pediatrics, Case \\ Western Reserve University, Cleveland, $\mathrm{OH}$ \\ ${ }^{2}$ Department of Epidemiology, Johns Hopkins University, Baltimore, MD \\ ${ }^{3}$ Division of Nephrology, Children's Hospital of Philadelphia, Philadelphia, PA \\ ${ }^{4}$ Division of Pediatric Nephrology, Children's Mercy Hospital, Kansas City, MO
}

\begin{abstract}
Objective-To define glomerular filtration rate (GFR) decline, hypertension (HTN) and proteinuria in subjects with autosomal recessive polycystic kidney disease (ARPKD) and compare with two congenital kidney disease control groups in the Chronic Kidney Disease in Children (CKiD) cohort.

Study design-GFR decline (iohexol clearance), rates of HTN (ambulatory/casual blood pressures (BPs)), antihypertensive medication usage, left ventricular hypertrophy (LVH) and proteinuria were analyzed in subjects with ARPKD $(n=22)$ and two control groups: aplastic/ hypoplastic/dysplastic $(n=44)$ and obstructive uropathies $(n=44)$. Differences between study groups were examined by Wilcoxon rank sum test.
\end{abstract}

Results-Annualized GFR change in subjects with ARPKD was $-1.4 \mathrm{ml} / \mathrm{min} / 1.73 \mathrm{~m}^{2}(-6 \%)$, with higher decline in subjects age $>10$ years $(-11.5 \%)$. However, overall rates of GFR decline did not differ significantly in subjects with ARPKD vs. controls. There were no significant differences in HTN or LVH rates, but subjects with ARPKD had a higher percent on $\geq 3$ BP medications (32\% vs. $0 \%, \mathrm{p}<0.0001)$, more ACE inhibitor use ( $82 \%$ vs. $27 \%$ vs. $36 \%, \mathrm{p}<0.0005)$, and less proteinuria (urine protein: creatinine $=0.1$ vs. $0.6, \mathrm{p}<0.005$ ).

Conclusions-This study reports rates of GFR decline, HTN and proteinuria in a small but wellphenotyped ARPKD cohort. The relatively slow rate of GFR decline in subjects with ARPKD and absence of significant proteinuria suggest that these standard clinical measures may have limited utility in assessing therapeutic interventions and highlight the need for other ARPKD kidney disease progression biomarkers.

Corresponding Author Katherine M Dell, M.D., 9500 Euclid Avenue, A12-800E, Cleveland, OH 44195, Phone: 216-444-6123; Fax 216-448-6015; Katherine.Dell@case.edu.

* List of additional members of CKiD Study is available at www.jpeds.com (Appendix).

The authors declare no conflicts of interest.

Portions of the study were presented as a poster at the meeting of the American Society of Nephrology, 2014. 


\section{Keywords}

GFR decline; pediatric; hypertension; proteinuria

Autosomal recessive polycystic kidney disease (ARPKD) affects approximately 1 in 20,000 children and is genetically and clinically distinct from the more common autosomal dominant form (ADPKD). ${ }^{1}$ ARPKD was previously considered a uniformly fatal disease in affected newborns, but with modern neonatal care, overall mortality has improved significantly More than $70 \%$ survive beyond the newborn period and $>80 \%$ of those survive beyond ten years of age. ${ }^{2}$ ARPKD still carries significant morbidity, with over $40 \%$ of patients progressing to end-stage renal disease (ESRD) by age 15 years. ${ }^{2}$ The phenotype of ARPKD, however, is quite variable: some patients progress to ESRD in infancy, whereas others may not require renal replacement therapy until later childhood and adolescence. ${ }^{3} \mathrm{~A}$ smaller subset present primarily with liver manifestations, typically in adolescence and young adulthood. ${ }^{4}$

Despite the significant mortality and morbidity in this population, prospectively collected data on ARPKD progression are very limited. Most studies have relied on retrospective analyses and/or registries, which have inherent limitations. ${ }^{3-5}$ One prospective study reported measured glomerular filtration rates (GFRs) obtained by 24-hour creatinine clearance measurements, but did not report rates of GFR decline over time. ${ }^{6}$ Factors that may contribute to kidney disease progression, specifically hypertension and proteinuria, have also not been well characterized.

The need for these progression data is highlighted by the emergence of novel therapies that may slow disease progression. Although there are currently no disease-specific therapies that have been applied in patients with ARPKD, a number of therapies have shown promise in ARPKD animal models. ${ }^{7,8}$ Unfortunately, development of treatment trials in patients with ARPKD is hampered by the paucity of prospective data on GFR decline. In addition, surrogate markers for kidney disease progression, especially magnetic resonance imaging (MRI) measurements of kidney volume used to quantitate kidney disease progression in ADPKD, ${ }^{9}$ are not valid in ARPKD, as kidney size does not increase with progressive disease. ${ }^{10}$

The objective of this study was to describe the rates of GFR decline, hypertension and proteinuria in subjects with ARPKD currently enrolled in the prospective Chronic Kidney Disease in Children (CKiD) study. We also compared findings in the subjects with ARPKD with those of two control groups with other congenital renal diseases also enrolled in CKiD in order to better identify ARPKD-specific kidney disease progression features that might differ from those of other congenital renal diseases.

\section{METHODS}

Subjects with ARPKD and controls were selected from among those enrolled in CKiD, a longitudinal, prospective study of children with mild-moderate chronic kidney disease (CKD). Over 50 pediatric nephrology sites in the United States and Canada have 
participated and/or continue to participate in the study. The inclusion and exclusion criteria for participation in the study have been reported in detail elsewhere ${ }^{11}$ (ClinicalTrials.gov: NCT00327860). Specific entry criteria relevant to this study include age 1-16 years, estimated GFR of $30-90 \mathrm{ml} / \mathrm{min} / 1.73 \mathrm{~m}^{2}$, absence of prior solid organ or hematopoietic stem cell transplant and absence of severe syndromic disease. Subjects enrolled in CKiD undergo baseline evaluations, then yearly follow-up visits. The current study included all subjects with ARPKD currently enrolled in CKiD. Matched controls were obtained from two diagnostic groups with other congenital renal diseases: (1) aplastic/hypoplastic/dysplastic disorders $(\mathrm{A} / \mathrm{H} / \mathrm{D})$; and (2) obstructive uropathies (OU). These groups were chosen as they were likely to have a similar age distribution as the subjects with ARPKD and are also primarily tubulointerstitial diseases. Matching was performed in order to distinguish ARPKD-specific clinical features from those related to early onset CKD in general.

Participants enrolled in CKiD undergo yearly determination of estimated GFR (eGFR) by the updated biomarker-based Schwartz GFR estimating formula, eGFR $(\mathrm{ml} / \mathrm{min}$ per 1.73 $\left.\mathrm{m}^{2}\right)=39.8[\mathrm{ht}(\mathrm{m}) / \mathrm{Scr}(\mathrm{mg} / \mathrm{dl})]^{0.456}[1.8 / \text { cystatin C }(\mathrm{mg} / \mathrm{l})]^{0.418}[30 / \mathrm{BUN}(\mathrm{mg} / \mathrm{dl})]^{0.079}$ $\left[1.076^{\mathrm{male}}\right][\mathrm{ht}(\mathrm{m}) / 1.4]^{0.179}$ and every other year measurements of GFR utilizing iohexol clearance (iGFR). ${ }^{12}$ This eGFR formula has show strong correlation with corresponding iGFR measurements $(\mathrm{R}=0.92) .{ }^{12}$ An analysis of subjects with ARPKD confirmed a similar strong correlation between eGFR and iGFR ( $R=0.96$, data not shown). Only subjects with at least two GFR measurements, whether iohexol-measured or estimated, were included. Subjects with ARPKD were matched 1:2 with A/D/H or OU controls for baseline GFR, age at study entry and at diagnosis. The primary outcome examined in this study was rate of GFR decline, reported both as percent (\%) decline and absolute decline (expressed as GFR change in $\mathrm{ml} / \mathrm{min} / 1.73 \mathrm{~m}^{2} /$ year). Both iGFR and eGFR were used in progression calculations, with preference given to iGFR where available. ${ }^{13}$ Blood pressure control and rates of LVH and proteinuria were also investigated as secondary outcomes.

Casual blood pressures were obtained by standardized auscultatory methods at yearly visits. Ambulatory blood pressure monitoring (ABPM) was performed every two years utilizing the SpaceLabs 90217 oscillometric device (SpaceLabs Healthcare, Issaquah, WA).

Echocardiography was also performed every two years to assess for the presence of left ventricular hypertrophy ( $\mathrm{LVH}$ ), defined as $\mathrm{LV}$ mass $\geq 95^{\text {th }}$ percentile (indexed to $\mathrm{Ht}^{2.7}$ for age and sex). Methods for obtaining casual blood pressures, ABPMs and echocardiograms have been described elsewhere. ${ }^{14,15} \mathrm{~A}$ subject was considered to have casual hypertension (HTN) if the baseline blood pressure at the first visit was $\geq 95^{\text {th }}$ percentile for age/sex/height percentile. ${ }^{16}$ Ambulatory HTN was defined as mean wake or sleep systolic blood pressure (SBP) or diastolic blood pressure (DBP) $\geq 95^{\text {th }}$ percentile or wake or sleep SBP or DBP load $\geq 25 \%$ according to published data. ${ }^{17}$ Proteinuria was defined as a urine protein to creatinine ratio (UP/C) of $\searrow 0.2 \mathrm{mg} / \mathrm{mg}$ from first morning specimens obtained at yearly visits.

\section{Statistical analyses}

Demographic and clinical characteristics were reported as median [interquartile range] or number, $\mathrm{n}$ (percent, \%) for each group and compared descriptively between groups. Annualized percent and absolute change in GFR were calculated using individual 
regressions (loglinear and linear, respectively) for each subject incorporating all available follow-up measurements. Differences (ARPKD vs. each control group) were tested by Wilcoxon rank-sum test or Fisher's exact test. Matched differences were calculated as the difference between the value of a subject with ARPKD and the average value of the two matched controls, and these distributions were tested for difference from zero by Wilcoxon signed rank test. As a subanalysis, we stratified subjects with ARPKD and control groups by baseline GFR ( $\geq 45$ and $<45 \mathrm{ml} / \mathrm{min} / 1.73 \mathrm{~m}^{2}$ ) or age at study entry ( $\geq 10$ and $<10$ years). All analyses were performed in SAS 9.3 (SAS Institute, Cary, NC).

\section{RESULTS}

The baseline demographic and clinical features of the subjects with ARPKD and two control groups are shown in Table I. Subjects with ARPKD and controls were successfully matched on the selected factors; specifically, baseline GFR, age at study entry and age at diagnosis were not significantly different between the subjects with ARPKD and both control groups. The vast majority of subjects were diagnosed before one year of age. Notably, there were more males in the OU group, likely due to the preponderance of subjects with posterior urethral valves in that subgroup. There were also more African Americans in the OU control group compared with the ARPKD group, but this difference was not seen in comparisons of subjects with ARPKD with the A/H/D control group. Similarly, the ARPKD group had more subjects who were of Hispanic ethnicity compared with the A/H/D group, but this difference was not seen in comparisons with the OU group. Rates of prematurity (gestational age less than 36 weeks) or low birth weight (less than $2500 \mathrm{~g}$ ) were similar in all three groups.

\section{Renal function (GFR) decline}

Baseline GFR and rates of GFR decline, including both annualized absolute and percent change, for the subjects with ARPKD and two control groups are summarized in Table II. Subjects with ARPKD showed a median absolute decline in GFR of $-1.4 \mathrm{ml} / \mathrm{min} / 1.73 \mathrm{~m}^{2}$ per year and a percent decline of $6 \%$ per year. This was not significantly different from that of the A/H/D group or the OU group. Analysis of the paired differences in percent GFR decline showed no significant differences between the subjects with ARPKD and either control group (data not shown). Because baseline GFR and puberty/older age have been associated with more rapid decline in renal function, ${ }^{18,19}$ we performed subanalyses to examine the impact of these two factors on GFR decline. Subjects with ARPKD and control subjects were stratified into two baseline GFR groups: GFR $<45$ or $\geq 45 \mathrm{ml} / \mathrm{min} / 1.73 \mathrm{~m}^{2}$ and two age groups: $<10$ vs. $\geq 10$ years of age. Results are summarized in Table III. For both ARPKD and control groups, subjects with baseline GFR $<45 \mathrm{ml} / \mathrm{min} / 1.73 \mathrm{~m}^{2}$ showed increased rates of GFR decline compared with those with higher GFRs. In terms of differences related to age, it was notable that subjects with ARPKD who were $\geq 10$ years of age showed an $11.5 \%$ per year decline in GFR, which was more than double the rate in subjects with ARPKD $<10$ years of age. The OU group also showed faster GFR decline in older subjects, whereas the $\mathrm{A} / \mathrm{H} / \mathrm{D}$ group did not. Statistical testing was not performed due to small numbers in some subgroups. 


\section{Hypertension, LVH and proteinuria}

Rates of hypertension, LVH, anti-hypertensive medication use, and proteinuria are summarized in Table IV. Subjects with ARPKD had similar baseline blood pressures when compared with the A/H/D and OU controls, and there were no significant differences in rates of casual or ambulatory hypertension between subjects with ARPKD and either control group. Rates of LVH also did not differ significantly between subject and control groups. The subjects with ARPKD did, however, have more antihypertensive use, with over $80 \%$ requiring anti-hypertensive medications. Notably, 32\% of subjects with ARPKD were on 3 or more anti-hypertensive medications, whereas none of the control subjects required that number. Subjects with ARPKD also had more angiotensin converting enzyme inhibitor (ACEI) and angiotensin receptor blocker (ARB) use compared with the controls. In contrast, the subjects with ARPKD had significantly less proteinuria than either control group. Median urine UPC in ARPKD was 0.1 vs. 0.6 in both of the control groups ( $\mathrm{p}<0.005)$. Only $27 \%$ of subjects with ARPKD had proteinuria (UPC $>0.2 \mathrm{mg} / \mathrm{mg}$ ) whereas $68 \%$ of the $\mathrm{A} / \mathrm{H} / \mathrm{D}$ control group and $77 \%$ of the OU control group had proteinuria $(\mathrm{p}<0.005$ subjects with ARPKD vs. each control group).

\section{DISCUSSION}

Cystic kidney disease in ARPKD is characterized by normal collecting tubule (CT) formation followed by development of progressive fusiform dilatation of the CTs. ${ }^{1}$ The disorder affects all CTs, with fusiform cysts progressively replacing normal parenchyma over time. This ongoing active cystogenic process is accompanied by development of tubulointerstitial fibrosis. This pathophysiology is in contrast to obstructive uropathies and congenital dysplasias, in which damage or abnormalities occur during tubular development. Despite these differences in underlying pathogenesis, there were no significant differences in percent or absolute GFR decline in the subjects with ARPKD compared with the two control groups. The subjects with ARPKD had a relatively slow median annualized GFR decline $\left(-1.4 \mathrm{ml} / \mathrm{min} / 1.73 \mathrm{~m}^{2}\right.$ or $6 \%$ per year) but also showed substantial variability (IQR, 1-10\% decline per year). Overall, the absolute declines in all three groups were relatively slow, with overall rates of GFR decline less than $3 \mathrm{ml} / \mathrm{min} / 1.73 \mathrm{~m}^{2} /$ year.

Specific risk factors for ARPKD kidney disease progression have not been reported previously. Older age/puberty and lower baseline GFR, however, were recently shown to impact pediatric CKD progression. ${ }^{18-20}$ In subanalyses, we examined rates of GFR decline in the subjects with ARPKD and two control groups, stratified by subject age or baseline GFR. subjects with ARPKD with lower baseline GFRs had higher rates of GFR decline than those with more intact baseline function. Although small numbers precluded statistical comparisons, both control groups also demonstrated higher rates of GFR decline in subjects with lower baseline GFRs. Strikingly, we found a strong association between age and GFR decline in the subjects with ARPKD with those $\geq 10$ years of age having a decline rate of $11.5 \%$ per year, over twice that of younger children. The OU control group also showed higher rates of decline with older age, though not as dramatic, whereas the $\mathrm{A} / \mathrm{H} / \mathrm{D}$ group did not. 
Hypertension is a well-established risk factor that is known to influence kidney disease progression in a wide variety of kidney diseases. ${ }^{20} \mathrm{~A}$ previous publication that examined neurocognition in ARPKD reported data on hypertension and blood pressure medication use in this ARPKD cohort and the A/H/D control group. ${ }^{21}$ In the current study, we expanded on those findings by examining the rates of hypertension and antihypertensive medication use in subjects with ARPKD in comparison with both A/H/D and OU patient groups. We also examined LVH rates, which had not been previously reported in the ARPKD cohort. Consistent with the well-known early and severe hypertension that is characteristic of ARPKD kidney disease, and with the previous published data, the subjects with ARPKD had significantly greater anti-hypertensive medication use compared with either control group. In fact, one-third of subjects with ARPKD were taking 3 or more anti-hypertensive medications, whereas none of the control subjects were. Despite the high anti-hypertensive requirements in the subjects with $A R P K D$, the rates of LVH did not differ among the three groups, suggesting that blood pressure control was similar in the three groups.

Proteinuria is also an important risk factor for kidney disease progression and several recent studies have highlighted its association with progression in both glomerular and nonglomerular disease in pediatric patients. ${ }^{13,20}$ Although progression rates were similar in the subjects with ARPKD compared with the two control groups, the subjects with ARPKD had significantly lower rates of proteinuria compared with either of the control groups. There were, in fact, no subjects with ARPKD with heavy proteinuria (UPC $>2 \mathrm{~g} / \mathrm{g}$, data not shown). Because all three groups encompass subjects with non-glomerular/primary tubulointerstitial diseases, one might not have expected them to differ with respect to the degree of proteinuria. The subjects with ARPKD, however, had substantially higher rates of ACEI use, likely reflecting the prevailing practice of using these agents as first line therapy for management of hypertension in this disease. ${ }^{22}$ The decreased proteinuria rates in the subjects with ARPKD, therefore, may reflect greater ACEI use, although they may also reflect the underlying tubulointerstitial disease pathogenesis. Regardless of the underlying cause for the diminished proteinuria, the findings suggest that proteinuria does not predict progression in subjects with ARPKD.

This study had several important limitations. Most notably, the number of subjects with ARPKD was relatively small. Several other studies have included larger numbers of subjects, but, as noted previously, these were primarily retrospective studies and registry data that relied on voluntary self-reporting. ${ }^{3,4}$ The ARPKD natural history study included 73 genetically confirmed adult and pediatric subjects with ARPKD and prospectively collected data. ${ }^{6}$ However, although baseline GFR values on those subjects were reported, no data on serial GFRs or rates of progression were presented. That study also utilized 24-hour urine creatinine clearances rather than "gold standard" plasma clearance-based GFR measurements, such as the iohexol clearance methodology utilized in the CKiD study. In addition, a significant proportion of their population had undergone liver or kidney transplants at the time of evaluation. Another limitation of our study is the fact that the diagnosis of ARPKD in the CKiD cohort was made by the treating nephrologist on the basis of clinical information, genetic testing or both. Thus, we are not able to definitively exclude disorders that phenocopy ARPKD (eg, isolated cystic dysplasia). ${ }^{23}$ Finally, the CKiD cohort includes subjects with ARPKD with mild to moderate renal disease. Those who were most 
severely affected were typically excluded from entry based on GFR criteria (i.e., eGFR requirement of $>30 \mathrm{ml} / \mathrm{min} / 1.73 \mathrm{~m}^{2}$ ) and/or a history of antecedent solid organ transplantation (including liver or kidney transplant). Thus, the data presented may not be generalizable to all patients with ARPKD.

Whereas this study provides data on rates of GFR decline, it also highlights the ongoing challenges of quantifying kidney disease progression in these subjects. The subjects with ARPKD had relatively low rates of GFR decline as well as substantial variability in GFR decline; their rates of proteinuria were also very low, in part likely the result of ACEI usage which also had a favorable impact on BP control. These findings suggest that a large number of patients would need to be studied for a long period of time in order to assess the impact of a therapeutic intervention using these standard clinical measures of progression. Given the rare occurrence of this disease, alternative biomarkers for ARPKD kidney disease progression are urgently needed in order to undertake therapeutic trials in ARPKD.

\section{Acknowledgments}

The CKiD Study is funded by the National Institute of Diabetes and Digestive and Kidney Diseases (NIDDK), the Eunice Kennedy Shriver National Institute of Child Health and Human Development, and the National Heart, Lung, and Blood Institute (U01-DK-66143, U01-DK-66174, U01DK-082194, U01-DK-66116). K.D. receives support from the NIDDK (R01-DK085099).

\section{Appendix}




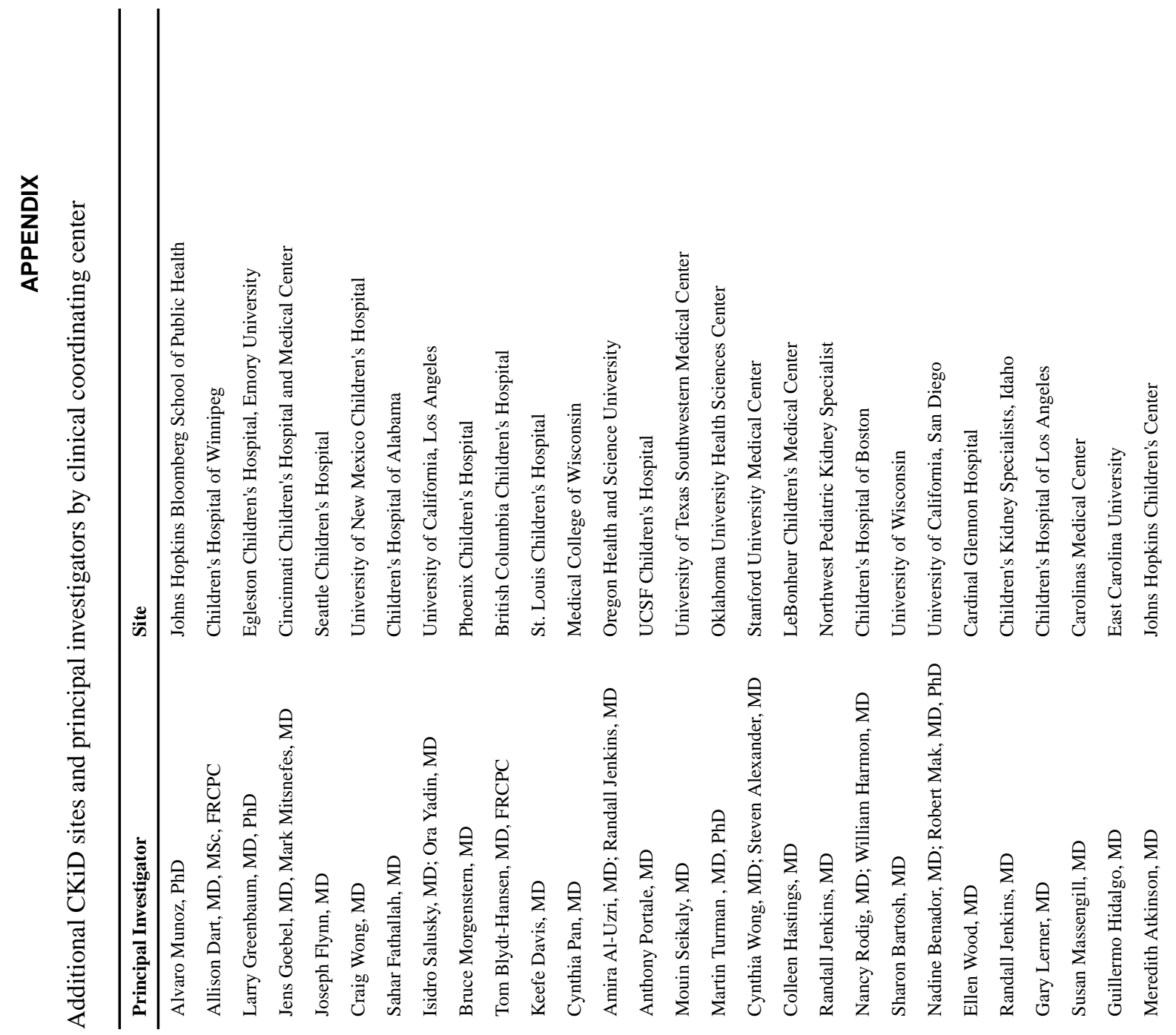




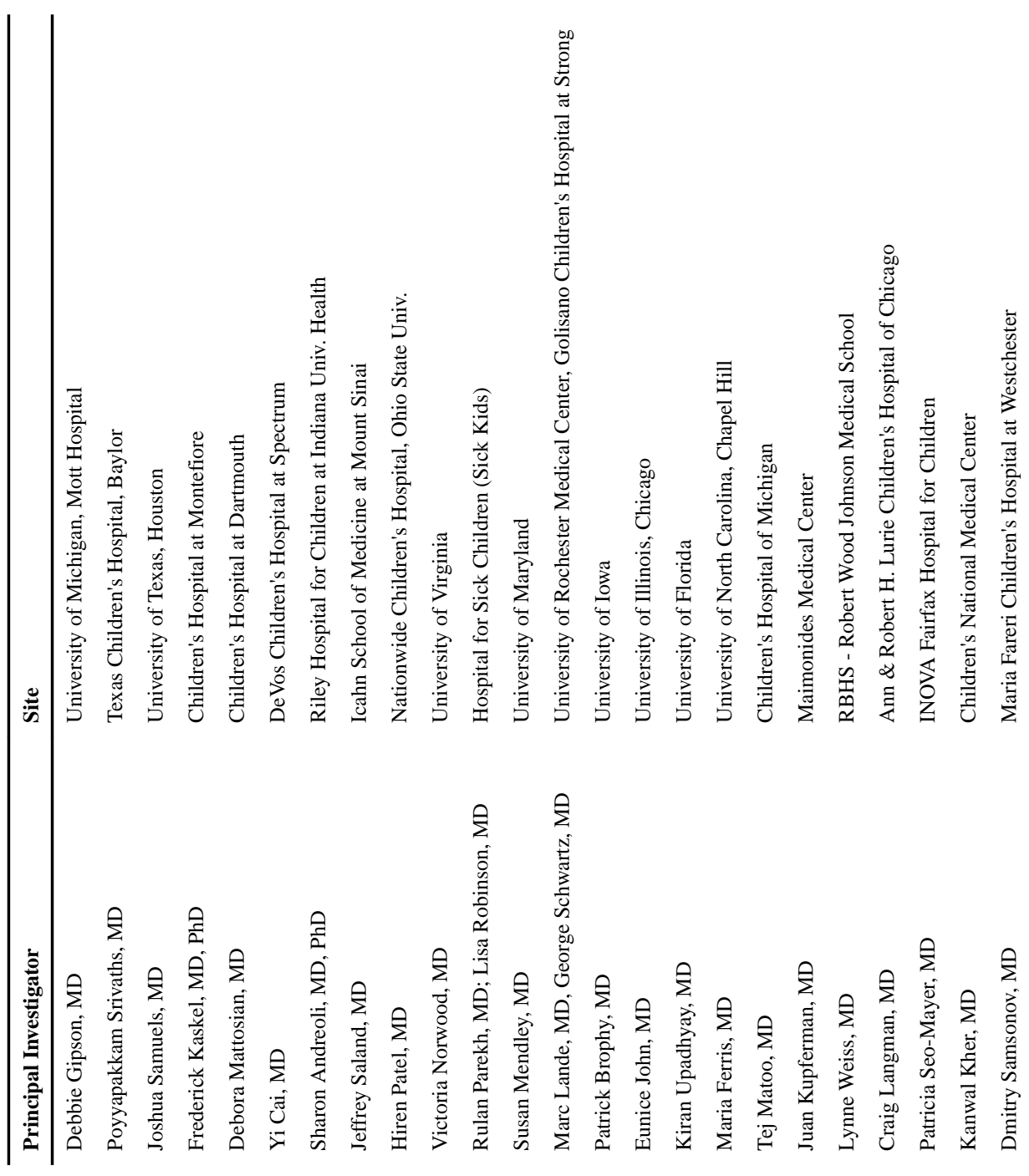

\section{References}

1. Dell KM. The spectrum of polycystic kidney disease in children. Advances in chronic kidney disease. 2011; 18:339-47. [PubMed: 21896375]

2. Roy S, Dillon MJ, Trompeter RS, Barratt TM. Autosomal recessive polycystic kidney disease: longterm outcome of neonatal survivors. Pediatr Nephrol. 1997; 11:302-6. [PubMed: 9203177]

3. Zerres K, Rudnik-Schoneborn S, Deget F, Holtkamp U, Brodehl J, Geisert J, et al. Autosomal recessive polycystic kidney disease in 115 children: clinical presentation, course and influence of gender. Arbeitsgemeinschaft fur Padiatrische, Nephrologie. Acta Paediatr. 1996; 85:437-45. [PubMed: 8740301]

4. Guay-Woodford LM, Desmond RA. Autosomal recessive polycystic kidney disease: the clinical experience in North America. Pediatrics. 2003; 111:1072-80. [PubMed: 12728091]

5. Capisonda R, Phan V, Traubuci J, Daneman A, Balfe JW, Guay-Woodford LM. Autosomal recessive polycystic kidney disease: outcomes from a single-center experience. Pediatr Nephrol. 2003; 18:119-26. [PubMed: 12579400]

6. Gunay-Aygun M, Font-Montgomery E, Lukose L, Tuchman M, Graf J, Bryant JC, et al. Correlation of kidney function, volume and imaging findings, and PKHD1 mutations in 73 patients with 
autosomal recessive polycystic kidney disease. Clin J Am Soc Nephrol. 2010; 5:972-84. [PubMed: 20413436]

7. Gattone VH 2nd, Wang X, Harris PC, Torres VE. Inhibition of renal cystic disease development and progression by a vasopressin V2 receptor antagonist. Nat Med. 2003; 9:1323-6. [PubMed: 14502283]

8. Masyuk TV, Masyuk AI, Torres VE, Harris PC, Larusso NF. Octreotide inhibits hepatic cystogenesis in a rodent model of polycystic liver disease by reducing cholangiocyte adenosine $3^{\prime}, 5^{\prime}$-cyclic monophosphate. Gastroenterology. 2007; 132:1104-16. [PubMed: 17383431]

9. Chapman AB, Guay-Woodford LM, Grantham JJ, Torres VE, Bae KT, Baumgarten DA, et al. Renal structure in early autosomal-dominant polycystic kidney disease (ADPKD): The Consortium for Radiologic Imaging Studies of Polycystic Kidney Disease (CRISP) cohort. Kidney Int. 2003; 64:1035-45. [PubMed: 12911554]

10. Blickman JG, Bramson RT, Herrin JT. Autosomal recessive polycystic kidney disease: long-term sonographic findings in patients surviving the neonatal period. AJR Am J Roentgenol. 1995; 164:1247-50. [PubMed: 7717240]

11. Furth SL, Cole SR, Moxey-Mims M, Kaskel F, Mak R, Schwartz G, et al. Design and methods of the Chronic Kidney Disease in Children (CKiD) prospective cohort study. Clin J Am Soc Nephrol. 2006; 1:1006-15. [PubMed: 17699320]

12. Schwartz GJ, Schneider MF, Maier PS, Moxey-Mims M, Dharnidharka VR, Warady BA, et al. Improved equations estimating GFR in children with chronic kidney disease using an immunonephelometric determination of cystatin C. Kidney Int. 2012; 82:445-53. [PubMed: 22622496]

13. Fathallah-Shaykh SA, Flynn JT, Pierce CB, Abraham AG, Blydt-Hansen TD, Massengill SF, et al. Progression of pediatric CKD of nonglomerular origin in the CKiD cohort. Clin J Am Soc Nephrol. 2015; 10:571-7. [PubMed: 25635034]

14. Mitsnefes M, Flynn J, Cohn S, Samuels J, Blydt-Hansen T, Saland J, et al. Masked hypertension associates with left ventricular hypertrophy in children with CKD. J Am Soc Nephrol. 2010; 21:137-44. [PubMed: 19917781]

15. Samuels J, Ng D, Flynn JT, Mitsnefes M, Poffenbarger T, Warady BA, et al. Ambulatory blood pressure patterns in children with chronic kidney disease. Hypertension. 2012; 60:43-50. [PubMed: 22585950]

16. The fourth report on the diagnosis, evaluation, and treatment of high blood pressure in children and adolescents. Pediatrics. 2004; 114:555-76. [PubMed: 15286277]

17. Soergel M, Kirschstein M, Busch C, Danne T, Gellermann J, Holl R, et al. Oscillometric twentyfour-hour ambulatory blood pressure values in healthy children and adolescents: a multicenter trial including 1141 subjects. J Pediatr. 1997; 130:178-84. [PubMed: 9042117]

18. Ardissino G, Testa S, Dacco V, Paglialonga F, Vigano S, Felice-Civitillo C, et al. Puberty is associated with increased deterioration of renal function in patients with CKD: data from the ItalKid Project. Arch Dis Child. 2012; 97:885-8. [PubMed: 22833407]

19. Ishikura K, Uemura O, Hamasaki Y, Ito S, Wada N, Hattori M, et al. Progression to end-stage kidney disease in Japanese children with chronic kidney disease: results of a nationwide prospective cohort study. Nephrol Dial Transplant. 2014; 29:878-84. [PubMed: 24516225]

20. Warady BA, Abraham AG, Schwartz GJ, Wong CS, Munoz A, Betoko A, et al. Predictors of Rapid Progression of Glomerular and Nonglomerular Kidney Disease in Children and Adolescents: The Chronic Kidney Disease in Children (CKiD) Cohort. Am J Kidney Dis. 2015

21. Hartung EA, Matheson M, Lande MB, Dell KM, Guay-Woodford LM, Gerson AC, et al. Neurocognition in children with autosomal recessive polycystic kidney disease in the CKiD cohort study. Pediatr Nephrol. 2014; 29:1957-65. [PubMed: 24828609]

22. Guay-Woodford LM, Bissler JJ, Braun MC, Bockenhauer D, Cadnapaphornchai MA, Dell KM, et al. Consensus expert recommendations for the diagnosis and management of autosomal recessive polycystic kidney disease: report of an international conference. J Pediatr. 2014; 165:611-7. [PubMed: 25015577] 
23. Guay-Woodford LM, Galliani CA, Musulman-Mroczek E, Spear GS, Guillot AP, Bernstein J. Diffuse renal cystic disease in children: morphologic and genetic correlations. Pediatr Nephrol. 1998; 12:173-82. [PubMed: 9630032] 


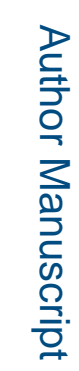

로을

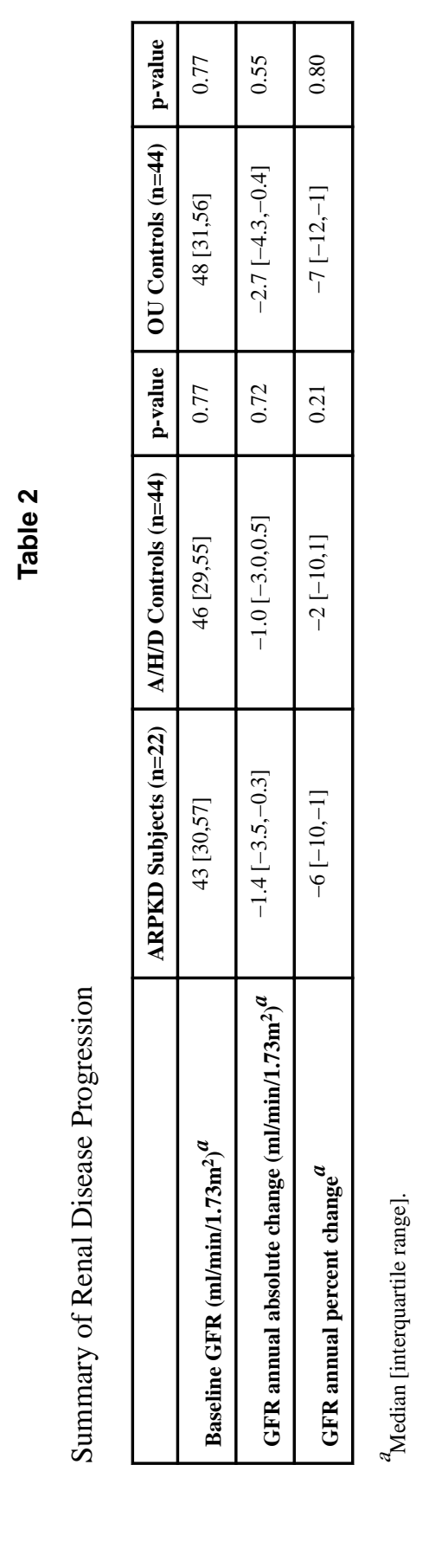

J Pediatr. Author manuscript; available in PMC 2017 April 01. 

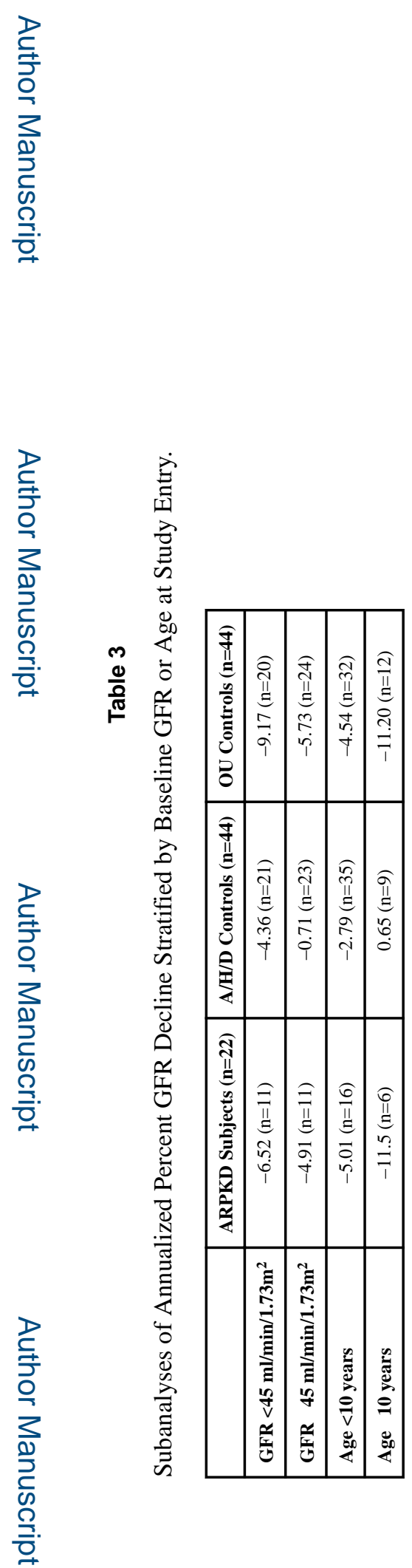

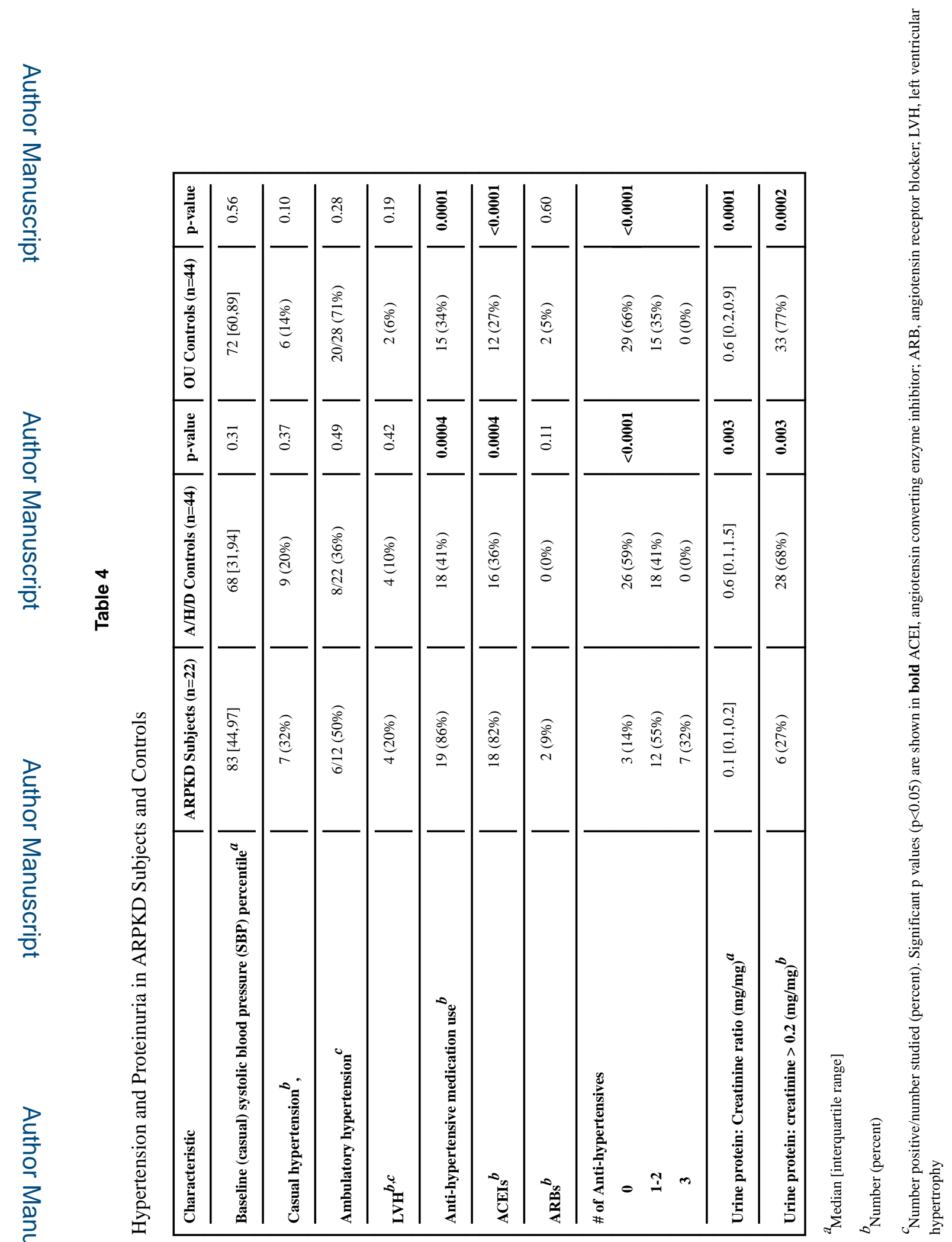

J Pediatr. Author manuscript; available in PMC 2017 April 01. 